\title{
2002s-76 \\ Enforcing Contracts: Should Courts Seek the Truth?
}

\author{
Claude Fluet
}

Série Scientifique
Scientific Series

\section{Montréal}

Septembre 2002

(C) 2002 Claude Fluet. Tous droits réservés. All rights reserved. Reproduction partielle permise avec citation du document source, incluant la notice (C).

Short sections may be quoted without explicit permission, if full credit, including $@$ notice, is given to the source.
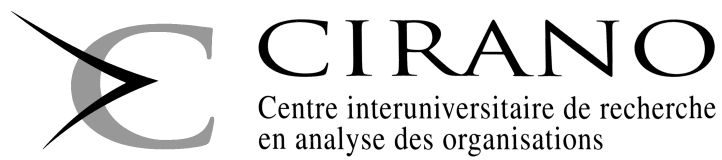

Centre interuniversitaire de recherche en analyse des organisations 


\section{CIRANO}

Le CIRANO est un organisme sans but lucratif constitué en vertu de la Loi des compagnies du Québec. Le financement de son infrastructure et de ses activités de recherche provient des cotisations de ses organisationsmembres, d'une subvention d'infrastructure du ministère de la Recherche, de la Science et de la Technologie, de même que des subventions et mandats obtenus par ses équipes de recherche.

CIRANO is a private non-profit organization incorporated under the Québec Companies Act. Its infrastructure and research activities are funded through fees paid by member organizations, an infrastructure grant from the Ministère de la Recherche, de la Science et de la Technologie, and grants and research mandates obtained by its research teams.

\section{Les organisations-partenaires / The Partner Organizations}

-École des Hautes Études Commerciales

-École Polytechnique de Montréal

-Université Concordia

-Université de Montréal

-Université du Québec à Montréal

-Université Laval

-Université McGill

-Ministère des Finances du Québec

-MRST

-Alcan inc.

- AXA Canada

-Banque du Canada

-Banque Laurentienne du Canada

- Banque Nationale du Canada

- Banque Royale du Canada

-Bell Canada

-Bombardier

-Bourse de Montréal

-Développement des ressources humaines Canada (DRHC)

-Fédération des caisses Desjardins du Québec

-Hydro-Québec

-Industrie Canada

-Pratt \& Whitney Canada Inc.

-Raymond Chabot Grant Thornton

-Ville de Montréal

Les cahiers de la série scientifique (CS) visent à rendre accessibles des résultats de recherche effectuée au CIRANO afin de susciter échanges et commentaires. Ces cahiers sont écrits dans le style des publications scientifiques. Les idées et les opinions émises sont sous l'unique responsabilité des auteurs et ne représentent pas nécessairement les positions du CIRANO ou de ses partenaires.

This paper presents research carried out at CIRANO and aims at encouraging discussion and comment.

The observations and viewpoints expressed are the sole responsibility of the authors. They do not necessarily represent positions of CIRANO or its partners. 


\title{
Enforcing Contracts: Should Courts Seek the Truth?*
}

\author{
Claude Fluet $\dagger$
}

\section{Résumé / Abstract}

J'analyse le cas où la réalisation d'un engagement contractuel n'est qu'imparfaitement vérifiable. La question posée est de savoir si le tribunal doit alors «dire le vrai » quant aux actions faisant l'objet d'un litige. Je montre que, du point de vue des contractants, la cour devrait faire abstraction d'une partie de l'information disponible et qu'elle devrait parfois statuer en faveur d'un des contractants, même si elle considère plus probable que l'autre ait raison. Cette analyse fournit une justification à certaines règles de procédure en droit civil et elle justifie le recours à des a priori normatifs neutres dans le règlement des différends.

I examine the case where fulfillment of a contractual commitment is only imperfectly verifiable and ask whether the court should then "tell the truth" regarding the action in dispute. I show that truth seeking does not maximize the expected surplus from contractual relationships. From the parties' viewpoint, the enforcer should disregard some of the available information and should sometimes rule in favor of one party, even though his understanding is that the other party is most probably right. The analysis provides a justification for rules of evidence in common law and for the use by courts of neutral normative priors regarding contending claims.

Mots clés : Jugements de cour, exécution des contrats, règles de procédure, standard de preuve, valeur de l'information.

Keywords: Adjudication, contract, enforcement, rules of evidence, standard of proof, value of information.

Codes JEL : D8, K4

\footnotetext{
* I wish to thank Urs Scheizer and Gerhard Wagner for their insights on an earlier draft and the participants of the JITE conference in Wörlitz for many useful comments. Financing from FCAR (Quebec) is gratefully acknowledged.

† Université du Québec à Montréal et CIRANO.fluet.claude-denys@uqam.ca.
} 


\section{Introduction}

A basic purpose of contracts is to formally allow the possibility of resorting to a third-party, whether a court or arbitrator, to enforce promises and settle disputes. In the quintessential contractual situation one party, the seller, agrees to perform some task for the benefit of another party, the buyer. Depending on how the contract is written, the seller may invest resources in the expectation of payment by the buyer upon completion of the task specified in the contract. Alternatively, the buyer pays up front with the expectation that the seller will later deliver. Intermediate arrangements are also possible, where the up-front payment is only a fraction of the total price or where the seller posts a bond to guarantee completion.

The contract is enforceable if a third-party with authority is able to verify completion of the action agreed upon. When payment is conditional on completion, the buyer will pay knowing that he would anyhow be forced to do so by the court. In turn, this induces the supplier to incur the necessary costs and deliver the good or service as required by the contract. Similarly, when payment is up-front, the supplier delivers since he would otherwise be forced to do so or be required to reimburse the buyer (or compensate him for foregone benefits, which must be more expensive still). Knowing this, the buyer has no reluctance to pay up-front. Of course, if the action is non verifiable or if third-party enforceability is too costly, the parties can only

rely, if at all, on informal self-enforcing devices such as reputation or repeated dealings.

This paper analyzes third-party enforcement when performance is only imperfectly verifiable. For instance, in service contracts with complex qualitative features the parties may have a clear idea of the level of service agreed 
upon, but this may be near to impossible to communicate to a third party. Even if the agreed standard is unambiguous, the third party will also often be at some informational disadvantage with respect to the parties regarding actual fulfillment. Suppose the supplier is a consulting firm which must produce a study on some particular issue. Presumably a third-party could easily detect a really sub-standard report, but in general it would be a matter of judgement whether the consultant did the appropriate research and calculations, in accordance with what would normally be expected of him.

Courts are often said to have a truth-detection function. I examine a simple situation where the only possible dispute between parties is whether or not a contractual commitment has been fulfilled (the possibility of efficient breach is excluded by assumption). When performance is perfectly verifiable, one expects courts to be useful if they are honest and speak truthfully. The question raised in the paper is whether truth-detection remains desirable when verifiability is potentially imperfect. Obviously, if information is imperfect, courts know that they may err. That is, they knows that they will sometimes give the wrong ruling as to whether the seller did or did not fulfill the contract. By truth-seeking I refer to a situation where courts nevertheless attempt to tell the truth as often as possible, subject to the accuracy of the evidence at their disposal. In disputes regarding fulfillment of a promise, truth-seeking courts decide on the basis of what is most probable given all the available information. From decision theory, such a strategy is known to maximize the probability of making correct decisions in the long run.

I show that truth-seeking courts are not in the ex ante interest of the parties. From their point of view, the perfect court is one whose decision rule maximizes the ex ante expected surplus from contractual relationships, which implies providing suppliers with appropriate incentives to fulfill the terms of 
the contract. Surplus-maximization requires that, on some occasions, courts be willing not to tell the truth as they see it. This does not mean they should be dishonest, but that sometimes they should rule in favor of one party, even though their understanding is that the other party is most probably right.

The discrepancy between 'truth-telling' and the provision of incentives is well known in principal-agent theory and is related to the time inconsistency of optimal contracts. Thus, in the basic principal-agent model, effort is implemented through a payment scheme conditioned on some imperfect performance indicator. Since the principal is fully committed to the scheme, the agent may then be penalized even though the principal 'knows' that the agent exerted the required level of effort.

In what follows I compare the decision rules of surplus-maximizing versus truth-seeking courts. The surplus-maximizing decision rule is easily characterized: courts should abstract from some of the information available to them and approach each case by initially putting equal weights on the parties' contradictory claims. They should then rule on the basis of what is most likely given the evidence about the case at hand, irrespective of their knowledge of how suppliers generally behave in similar cases or of their understanding of the particular supplier's incentives to fulfill the contract. The difference with truth-seeking relates to the courts' priors about the validity of the claims. Truth-seeking courts rely on their overall knowledge and understanding to formulate rational or situation-consistent priors about these claims. Surplus-maximizing courts use neutral normative priors, which they know to be incorrect.

The present results draw on Demougin and Fluet (2002). That paper analyzes the efficiency properties, from an incentive point of view, of the standard of proof for a ruling of negligence in tort cases. We show that the 
'preponderance of evidence' standard in common law induces maximum incentives to exercise care, provided the standard is interpreted in terms of the relative likelihood of due care versus negligence. ${ }^{1}$ Relative likelihood is meant in the usual mathematical sense, as in non Bayesian decision making. It is argued that ordinary 'rules of evidence' warrant such an interpretation, since they lead to the exclusion of apparently relevant information. In particular, according to such rules, judges or jurors are supposed to rid themselves of all prior beliefs and to begin a trial as if they knew nothing factual. The inconsistency between evidentiary rules and Bayesian decision making has been strongly emphasized recently in Daughety and Reinganum [2000a, 2000b].

I make a similar point in the present paper, although the setting is a contractual dispute. Surplus-maximizing courts decide on a preponderance of evidence in terms of relative likelihood, disregarding some of the information at their disposal. By contrast, truth-seeking is an instance of standard Bayesian decision making on the basis of all available information. I extend the argument by comparing the sequential equilibria resulting from either type of decision rule. I show that whether a surplus-maximizing rule favors the buyer (or the seller) more or less often than under truth-seeking depends on the accuracy of information. I also discuss the value of information under either rule. ${ }^{2}$

\footnotetext{
${ }^{1}$ Our results hold even if the parties may submit partial or biased evidence and the court does not know how well informed the parties are. The properties of the preponderance standard with non discrete action are analyzed in Fluet [1999]. The disincentive effects of court error are well known in the law in economics literature (e.g. Polinsky and Shavell [1989] and Kaplow and Shavell [1994]).

${ }^{2}$ The equilibrium implications, in a tort law setting, of what amounts to truth-telling are examined in Hylton (1990), but with exogenous type I and type II errors. In a different context but in the spirit of the present analysis, Lewis and Poitevin (1997) analyze the equilibrium effect of modifying the standard of proof or of changes in accuracy, when the
} 
The next two sections describe the contractual setting and the courts' information for verifying performance. The main results are in sections 4 and 5 which compare sequential equilibria under truth-seeking and surplusmaximization. Section 6 draws implications regarding the value of information and the role for 'evidentiary rules' aimed at excluding information.

\section{The model}

A party contracts with another for the undertaking of some task or project. The buyer's benefit from a half completed project is $v_{l}$ and the seller's cost is $c_{l}<v_{l}$. If fully completed, the project is worth $v_{l}+v$ and $\operatorname{costs} c_{l}+c$. At the contracting date, $v_{l}, c_{l}$ and $v$ are common knowledge and both parties know that $c$ is distributed according to the c.d.f. $G(c)$ with density $g(c)>0$ on the interval $[\underline{c}, \bar{c}]$, where $\bar{c} \leq v$. The value of $c$ becomes known only to the seller during the course of the project, once he has half completed the action and therefore expended $c_{l}$. At that point the seller decides whether he will indeed complete the task, in which case he incurs the additional $\operatorname{costs} c$.

When all is done, the court is able to verify whether some action has been undertaken by the seller, as opposed to no action at all. However, it can only imperfectly verify whether there has been full completion as opposed to half completion. One interpretation is that $v_{l}$ refers to a low-quality variant of the project, while $v_{l}+v$ is the high quality. The court cannot perfectly distinguish between high and low quality, but would know if nothing has been done. The sequence of events and actions is depicted in figure 1 .

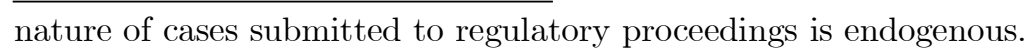




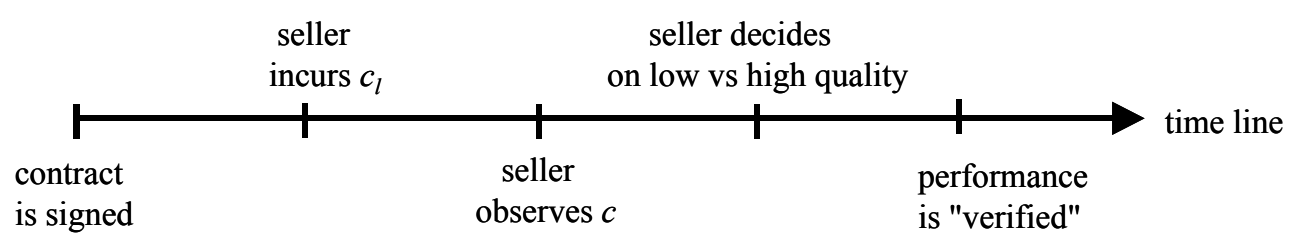

Figure 1

If quality were completely unverifiable, the parties would contract for the low quality since this is worthwhile by itself (i.e. $c_{l}<v_{l}$ ). If it were perfectly verifiable, they would contract for the high quality since $c<v$ with probability one. ${ }^{3}$ In the latter case, because of symmetric information at the contracting date, there always exists an arrangement maximizing the parties' expected surplus ex ante, i.e. inducing the seller to supply high quality. One such arrangement is the following. The buyer pays the total price $p$ up-front and the seller simultaneously posts a bond $b$ to be forfeited to the buyer if high quality is not delivered. These satisfy

$$
c_{l}+c_{e} \leq p \leq v_{l}+v .
$$

where $c_{e}$ is the expected value of $c$ and

$$
b \geq v_{l}+v .
$$

The first condition describes the participation constraints for both the buyer and the seller. The second inequality is an incentive compatibility condition. Once $c_{l}$ has been expended, the seller is better off completing the project because he loses $b$ if he does not, while his opportunity cost of doing so is some $c$ less than $v$. At the inception of the contract, he is also

\footnotetext{
${ }^{3}$ With $v_{l}=c_{l}=0$, the results in the next section would be essentially the same, but with 'no contract equilibria' substituting for 'low-quality contracts'.
} 
better off expending $c_{l}$ since otherwise he loses $b$ for sure, while his expected opportunity cost of delivering is $c_{l}+c_{e}<b$. By letting $p$ vary between the lower and upper bounds in (1) and choosing $b$ to satisfy (2), any distribution of the ex ante gains to trade can be attained. Other arrangements are possible, but they are essentially equivalent if third-party enforcement is costless. For instance, the total price $p$ may be interpreted as being paid only upon completion, with the seller posting an actual performance bond of amount $b-p$.

Under imperfect verifiability, the court may err in the assessment of quality. Let $\alpha$ denote the probability that high quality is held not to have been delivered, when in fact it has. Let $\beta$ be the probability of the same ruling when the seller only supplied the low quality. Thus, $\alpha$ and $1-\beta$ are the type I and type II error respectively (where these come from will be described shortly). At the date of contract, parties take these probabilities as given. Under the previous contractual arrangement, and denoting by $l$ and $h$ the low and high quality respectively, a seller supplying the low quality has expected profit

$$
\pi_{l}=p-\underline{c}-\beta b
$$

A seller with cost $c$ supplying the high quality earns the profit

$$
\pi_{h}=p-\underline{c}-c-\alpha b .
$$

The possibility of court error creates a two-sided opportunism problem. The seller can get away with a half completed project with probability $1-\beta$. Conversely, the buyer has an incentive to claim that the task has not been performed as agreed, since there is a probability $\alpha$ that the court will be convinced even though the claim is false.

Once he has observed $c$, it is profitable for the seller to complete the 
project if $\pi_{h} \geq \pi_{l}$ or equivalently

$$
c \leq(\beta-\alpha) b \equiv \widehat{c}
$$

A contract for delivery of the high quality is therefore fulfilled with probability $G(\widehat{c})$. The seller's expected profit is

$$
\widehat{\pi}=p-c_{l}-\int_{\underline{c}}^{\widehat{c}} c g(c) d c-[G(\widehat{c}) \alpha+(1-G(\widehat{c})) \beta] b
$$

and the buyer's expected net benefit is

$$
\widehat{v}=v_{l}+G(\widehat{c}) v+[G(\widehat{c}) \alpha+(1-G(\widehat{c})) \beta] b-p .
$$

Total expected surplus is

$$
\widehat{s}=\widehat{v}+\widehat{\pi}=v_{l}-c_{l}+\int_{\underline{c}}^{\widehat{c}}[v-c] g(c) d c>0,
$$

the inequality being satisfied for any value of $\widehat{c}$.

Provided $\beta>\alpha$, court error clearly does not matter if money transfers between parties can be arbitrarily large, i.e. a first-best outcome is then always feasible. To see this, suppose $b$ is large enough for $\widehat{c}>\bar{c}$ to hold. Then the total expected surplus is the perfect information surplus

$$
v_{l}+v-c_{l}-c_{e}
$$

Furthermore, $\widehat{\pi} \geq 0$ and $\widehat{v} \geq 0$ if the price $p$ paid up-front satisfies

$$
c_{l}+c_{e}+\alpha b \leq p \leq v_{l}+v+\alpha b
$$

Of course, from (5) and (9) this may require arbitrarily large transfers $p$ and $b$ if $\beta-\alpha$ is very small (although positive) and $\alpha>0$.

I assume that feasible money transfers between the parties are bounded. A standard justification is that the parties have limited wealth. Thus, $p$ must 
be bounded above by the buyer's wealth; from the participation constraint (9), this restricts the $b$ 's that can be agreed upon. Another possible justification is that the common law tradition prevents courts from enforcing penalty clauses in contracts. Penalty clauses refer to terms stipulating damages that exceed the actual harm caused by non performance. In the present context, this means that courts would be reluctant to enforce damages of amount $b$ that are out of proportion with what would be needed to compensate the buyer.

For simplicity, I focus on the second justification and assume that the seller can at most be made to compensate the buyer for foregone benefits, given the terms of the contract. Suppose as before that the buyer pays $p$ upfront. If the seller is found (possibly erroneously) to have delivered only the low quality, he is forced to pay $v$ to the buyer. Since the latter has already obtained $v_{l}$, his net benefit is then $v_{l}+v-p$ as promised in the contract. If the seller is found to have taken no action at all, which would be detected with certainty, he is made to pay $v_{l}+v$ to the buyer who therefore again obtains the same net benefit. ${ }^{4}$

The foregoing is equivalent to the seller forfeiting with certainty a bond equal to $v_{l}+v$ if he takes no action at all. Once he has already expended $c_{l}$, he risks forfeiting the bond $b=v$ if the court rules that he has not completed the task. From (5), once $c$ is observed, the seller therefore has an incentive to complete only if

$$
c \leq(\beta-\alpha) v \equiv \widehat{c} .
$$

The parties can always at least agree to a contract for the low quality.

\footnotetext{
${ }^{4}$ This corresponds to 'expectation damages' in common law, whereby the promisee is restored to the benefits he would have obtained if the promise had been kept (see for instance Cooter and Uhlen [2000])
} 
Whether the agreement will in fact specify the high quality depends on whether the latter can be expected to be supplied with positive probability.

Result 1: A contract is always agreed upon, whether for the low or the high quality. It specifies the high quality if

$$
(\beta-\alpha) v>\underline{c} .
$$

\section{Court decisions}

Ex post the parties jointly observe evidence - various facts, written opinions by experts, etc. - that can be costlessly communicated to the third-party. Since any piece of information favors one party or the other, all relevant evidence is always communicated (or rather the result is the same as if it had been, see Milgrom and Roberts [1986]). The outcome of the parties' disclosure decisions and of the confrontation of expert opinion is modeled as if the court observed a signal $x$ correlated with the seller's action. The signal is distributed according to the c.d.f. $F_{i}(x)$ with density $f_{i}(x)>0$ on the unit interval $[0,1]$, where $i=h, l$ denotes the action; furthermore, $x$ satisfies MLRP with the likelihood ratio $f_{l}(x) / f_{h}(x)$ strictly decreasing on the support, meaning that high quality appears relatively more likely for large values of the signal.

The assumptions concerning the signal are without loss of generality. The actual evidence and outcome of the parties' confrontation before the third party might be a 'complex' random vector $\left(z_{1}, \ldots, z_{N}\right)$ with densities $h_{i}\left(z_{1}, \ldots, z_{N}\right)$ for $i=h, l$. However, whether he is truth-seeking or surplus 
maximizing, the third party's decision will turn out to depend on the evidence only through the likelihood ratio $h_{l} / h_{h}$. A monotonic transformation

$$
x=\varphi\left[h_{l}\left(z_{1}, \ldots, z_{N}\right) / h_{h}\left(z_{1}, \ldots, z_{N}\right)\right]
$$

can then always be found such that $x$ is a sufficient statistic satisfying MLRP and with the unit interval as support. ${ }^{5}$ The underlying assumption is that the possible evidence on which the court will base its ruling is indeed 'complex' and cannot be directly contracted upon by the parties. Nevertheless, that evidence can help the court form an 'opinion' as to what occurred. In effect, the parties are constrained to contracts specifying transfers contingent on the court's opinion regarding the seller's performance.

\section{Surplus-maximization}

The court's decision rule implies some $\alpha$ and $\beta$, leading to the cost threshold $\widehat{c}=v(\beta-\alpha)$ for the seller to actually deliver high quality. The decision rule is surplus-maximizing if the resulting type I and type II error are such as to maximize

$$
\widehat{s}=v_{l}-c_{l}+\int_{\underline{c}}^{\widehat{c}}[v-c] g(c) d c .
$$

A sufficient condition is that $\widehat{c}$ be made as large as possible (this is necessary if the largest feasible $\widehat{c}$ is less than $\bar{c}$ ). It follows that the appropriate decision rule maximizes the probability $\beta$ of penalizing a non-performing seller, for some type I error $\alpha$ of penalizing a performing one. The foregoing amounts to the characterization of an efficient test of hypothesis in classical statistics.

\footnotetext{
${ }^{5}$ In a test about a simple hypothesis ( $h$ versus $l$ ), all realizations of $\left(z_{1}, \ldots, z_{N}\right)$ can be ordered in terms of 'more favorable than' in the sense of Milgrom [1981], hence the existence of a scalar sufficient statistic satisfying MLRP.
} 
From Neyman and Pearson's lemma, this means that the seller should be held not to have performed if the likelihood ratio $f_{l}(x) / f_{h}(x)$ is greater than some critical value. ${ }^{6}$ Given MLRP, the court must rule that the seller has not fulfilled the contract when observing $x<\widehat{x}$, for some critical $\widehat{x}$.

The cost threshold $\widehat{c}$ for the seller to actually deliver high quality therefore satisfies

$$
\widehat{c}=v(\beta-\alpha)=v\left[F_{l}(\widehat{x})-F_{h}(\widehat{x})\right] .
$$

Since MLRP implies first-order stochastic dominance, $\widehat{c}$ is strictly positive for any $\widehat{x} \in(0,1)$ and is zero when $\widehat{x}$ is zero or unity. Furthermore, it is easily seen that $\widehat{c}$ is a quasi-concave function of $\widehat{x}$. Threfore, maximizing the foregoing expression leads to the critical $\widehat{x}_{S}$ satisfying the first-order condition

$$
f_{l}\left(\widehat{x}_{S}\right)=f_{h}\left(\widehat{x}_{S}\right) .
$$

Denote the resulting cost threshold by $\widehat{c}_{S}$. The condition (14) is necessary if $\widehat{c}_{S} \leq \bar{c}$, meaning that the seller may then not always supply the high quality. When $\widehat{c}_{S}>\bar{c}$ the court could choose the critical value arbitrarily in some interval which includes $\widehat{x}_{S}$. For simplicity, I assume the latter is always chosen.

The surplus-maximizing decision rule has a simple interpretation. $f_{h}(x)$ and $f_{l}(x)$ are the likelihoods of the actions $h$ or $l$ given the evidence $x$ (i.e. the probability of observing $x$ if $h$ or $l$ has been undertaken). When the evidence is such that $f_{l}(x)>f_{h}(x)$, which occurs when $x<\widehat{x}_{S}$, low quality is more likely and the arbitrator rules accordingly. When $f_{h}(x)>f_{l}(x)$, high quality is more likely and the arbitrator holds that high care has indeed been delivered.

\footnotetext{
${ }^{6}$ Equivalently, in terms of the true 'complex' evidence, if $h_{l}\left(z_{1}, \ldots, z_{N}\right) / h_{l}\left(z_{1}, \ldots, z_{N}\right)$ is greater than some critical value.
} 


\section{Figures 2a and 2b about here}

The relative likelihood rule is illustrated in the figures $2 \mathrm{a}$ and $2 \mathrm{~b}$. Note that $G(\widehat{c})$, the probability of high quality being delivered, is itself a quasiconcave function of $\widehat{x}$. In 2a, not all sellers deliver the high quality as some find that their cost of doing so is greater than their private benefit. Nevertheless, the probability that the seller delivers is maximized given the circumstances. In figure $2 \mathrm{~b}$, the seller always provides the high quality even though verifiability is imperfect. Compared to the first figure, either the evidence is more informative, in the sense of greater verifiability of the seller's action, or $\bar{c} / v$ is smaller so that smaller incentives are required to induce performance.

The values $x_{1}$ and $x_{2}$ in the figures are the solutions to

$$
v\left[F_{l}(x)-F_{h}(x)\right]=\underline{c} .
$$

It may be that this equation has no solution. This occurs when at the critical value defined by the relative likelihood rule

$$
v\left[F_{l}\left(\widehat{x}_{S}\right)-F_{h}\left(\widehat{x}_{S}\right)\right]<\underline{c} .
$$

In this case, verifiability is very poor and the parties know that a promise to deliver the high quality will never be fulfilled, which means that they settle for the low quality contract.

Result 2: A surplus-maximizing court rules on the basis of the relative likelihood of performance versus non performance, i.e. it decides against the seller whenever $f_{l}(x)>f_{h}(x)$ and against the buyer otherwise.

The relative likelihood rule maximizes the probability of performance in a contract promising high quality, as well as the chances of such a contract 
being agreed upon in the first place. Clearly, if the parties could directly contract on transfers contingent on the ex post evidence, the critical regions specified in the contract would also be determined on the basis of relative likelihoods. In other words, a surplus-maximizing court is a perfect substitute for the contractibility of the evidence.

\section{Truth-seeking}

It is easy to see why truth-seeking courts may not be in the parties' interest. Take figure $2 \mathrm{~b}$ for instance and assume that, for some reason, the parties expect the court to assess performance on the basis of the critical value $\widehat{x}_{S}$. A rational court understanding the seller's incentives would then know that high quality has been delivered. Thus, it would conform to the parties' expectations only if it is willing not to 'tell the truth' when $x<\widehat{x}_{S}$.

Before taking into account the realization $x$ for the case at hand, a court has some 'prior' $\mu_{0}$ regarding the probability that high quality was delivered. This rests on its overall information and on its knowledge of the decision rule generally used by courts (and therefore of the incentives provided by court rulings). Up-dating on the basis of the particular $x$ in the case at hand, the court's posterior probability concerning high quality is then

$$
\mu_{1}(x)=\frac{\mu_{0} f_{h}(x)}{\mu_{0} f_{h}(x)+\left(1-\mu_{0}\right) f_{l}(x)} .
$$

This is a strictly increasing function of $x$, provided $\mu_{0} \neq 0,1$. When $\mu_{1}(x)>$ $1 / 2$, the court's understanding given all available information is that high quality is more probable. If it seeks the truth, it would rule in favor of the seller. Under truth-seeking, the courts' decision rule therefore implies a critical value $\widehat{x}$ which depends on priors (as before the quality is held to be 
low if $x<\widehat{x})$.

In equilibrium, the priors are situation consistent and therefore $\mu_{0}=G(\widehat{c})$ where $\widehat{c}$ depends on $\widehat{x}$ as in the foregoing section. Let $\widehat{x}_{T}$ denote an equilibrium cutoff with truth-seeking courts. Obviously $\widehat{x}_{T}=1$ is always an equilibrium: irrespective of $x$, courts then always hold that low quality has been delivered, which provides no incentives (i.e. $G\left(\widehat{c}_{T}\right)=0$ ) and implies that courts are right in their decision. By contrast, there can be no equilibrium where high quality is delivered with certainty since courts would rule accordingly, which also provides no incentives. If it exists, an equilibrium with a positive probability of high quality is therefore characterized by $\widehat{x}_{T} \in(0,1)$ solving

$$
\mu_{1}(\widehat{x})=\frac{G(\widehat{c}) f_{h}(\widehat{x})}{G(\widehat{c}) f_{h}(\widehat{x})+(1-G(\widehat{c})) f_{l}(\widehat{x})}=\frac{1}{2}
$$

where $\widehat{c}=v\left[F_{l}(\widehat{x})-F_{h}(\widehat{x})\right]$.

\section{Figures 3a, 3b and 3c about here}

If by coincidence $G\left(\widehat{c}_{S}\right)=1 / 2$ at the surplus-maximizing cutoff, then $\widehat{x}_{T}=\widehat{x}_{S}$ is a solution but this is of course non generic. If high quality is at all possible under truth-seeking, there are generally multiple equilibria. In the figures $3 \mathrm{a}$ to $3 \mathrm{c}$, I use the fact that condition (18) can be rewritten as

$$
\frac{f_{l}(\widehat{x})}{f_{h}(\widehat{x})}[1-G(\widehat{c})]=G(\widehat{c}) .
$$

For $x<\widehat{x}_{S}$, the left-hand side is strictly decreasing in $\widehat{x}$ while the right-hand side is increasing. In each figure, the 'good' equilibrium is at the intersection point $A$, as opposed to the equilibrium at $B$ (and the really 'bad' one at $\widehat{x}_{T}=1$ where (19) is not satisfied). 
Focusing on the 'good' outcome, to what extent does a truth-seeking equilibrium differ from surplus maximization? In the figures $3 \mathrm{a}$ and $3 \mathrm{~b}$, $G\left(\widehat{c}_{T}\right)>1 / 2$ and $\widehat{x}_{T}<\widehat{x}_{S}$. Compared with a surplus-maximizer, a truthseeker then needs more convincing evidence (i.e. a larger likelihood ratio $\left.f_{l} / f_{h}\right)$ to hold that low quality was delivered. This follows directly from the fact that surplus maximizing is similar to truth-seeking, but with 'neutral' priors equal to one half regarding high or low quality. Alternatively, one could say that situations then sometimes arise where a rational surplus maximizing court would know that it is 'unfairly' penalizing the seller. The opposite occurs at the good equilibrium $A$ in figure 3c. In this case $G\left(\widehat{c}_{T}\right)<1 / 2$ and $\widehat{x}_{T}>\widehat{x}_{S}$. Compared to a surplus-maximizer, a truth-seeking court then needs more convincing evidence to hold that good quality was provided. In this case, a rational surplus-maximizer would knowingly at times be 'unfair' to the buyer, ruling that he was supplied high quality but thinking the opposite is more probably true.

Everything else equal, which case arises depends on the extent to which the seller's action is verifiable. The more informative the evidence (as determined by the characteristics of $f_{h}$ and $f_{l}$ ), the larger the probability of high quality under surplus maximization. More informative evidence means a larger $\beta=F_{l}(\widehat{x})$ for any type I error $\alpha=F_{h}(\widehat{x})$. Geometrically, this induces an upward shift in the $G(\widehat{c})$ curve and therefore an increase in the probability $G\left(\widehat{c}_{S}\right)$ under surplus maximization. The next result characterizes the 'good' equilibria under truth telling using the outcome under surplus-maximization as benchmark (a formal proof is omitted but the argument follows readily from the figures).

REsult 3: Generically $G\left(\widehat{c}_{T}\right)<G\left(\widehat{c}_{S}\right)$. If the evidence is sufficiently informative for $G\left(\widehat{c}_{S}\right)>1 / 2$ to obtain, then $\widehat{x}_{T}<\widehat{x}_{S}$ and $G\left(\widehat{c}_{T}\right)>1 / 2$. If it is 
relatively uninformative so that $G\left(\widehat{c}_{S}\right)<1 / 2$, then $\widehat{x}_{T}>\widehat{x}_{S}$.

In other words, if the evidence has relatively good informational content, the probability of erroneously penalizing a seller delivering high quality (the type I error) is greater under surplus maximization than under truth-seeking. The opposite occurs if the evidence has weak informational content. In all cases, except the non generic situation alluded to above, truth-telling induces a lower probability of performance. ${ }^{7}$

\section{Discussion and concluding remarks}

Formal court procedures are characterized by 'rules of evidence' which exclude as inadmissible apparently relevant information. According to such rules, information such as 'evidence of character' or purely statistical information which could 'bias' opinion should not be considered. If such evidence has inadvertently been communicated, the judge or jury are required to ignore it in reaching a decision. In the context of the present model, exclusionary rules can be rationalized as a means of aligning courts tempted to seek the truth away from truth-seeking and more towards surplus-maximization.

The point that evidentiary rules may be justified for the purpose of providing incentives is also made by Daughety and Reinganum (2000): "It is plausible to interpret such rules as focusing decision making on the evidence provided at trial and discouraging the substitution of the fact finder's subjective prior for the evidence. To the extent that a decision relies on a (possibly

\footnotetext{
${ }^{7}$ An equilibrium with a positive probability of high quality may not exist under truthseeking, even though $G\left(\widehat{c}_{S}\right)>0$ under surplus maximization. This occurs when the relevant curves in the figures do not intersect (i.e. when the left-hand side of (19) is always greater than the right hand side).
} 
strong) subjective prior, this reliance reduces the incentives for the parties to provide evidence ... [and] the defendant's incentive to take care". Posner (1999) presents a similar argument and makes the additional point that rules of evidence allow 'non biased' priors: "Ideally we want the trier of fact to work from prior odds of 1 to 1 that the plaintiff ... has a meritorious case". ${ }^{8}$

Arbitrary subjective priors and biases clearly can do not good, whether for providing incentives nor for that matter for getting at the truth. However, in the model presented above the priors of a truth-seeking court are neither subjective nor biased. They are precisely those an objective outside observer (a 'social scientist') would want to hold, if he had the same general knowledge and was concerned with accuracy in the case at hand. Indeed, one could say that it is the surplus maximizing court which holds biased priors, which it presumably knows to be inconsistent with the situation.

The notion of bias has two different meanings here. For the 'social scientist', whose role is not to provide incentives but indeed to tell the truth, the absence of bias is interpreted in terms of rational priors, consistent with Bayesian decision making on the basis of all available information. By contrast, in Posner's statement, the absence of bias has the normative meaning of giving 'equal chances' to each parties' contention. The preceding analysis showed that such normative 'neutral' priors have useful efficiency properties from an incentive point of view - i.e. when the issue in dispute is the discretionary action of one of the parties.

Within the present framework, if the parties could choose the enforcer's decision rule, they would require the court to hold equal priors regarding the actions $h$ or $l$ and to up-date on the basis of $x$. Thus $x$ (together with its

${ }^{8}$ Prior odds differing from 1 to 1 are also described as 'biased' in Froeb and Kobayashi (1996) for instance. 
densities $f_{h}$ and $f_{l}$ ) would constitute the admissible evidence, as opposed to information of a general character such as the distribution $G(c)$. Of course, in the model the distinction between priors and up-dating is trivial since all cases submitted to the court are drawn from the same population and $x$ is the only piece of information specifically related to a particular dispute. But consider the following extension of the model. Suppose the seller's differential cost $c$ for the high quality can also become known to the court. ${ }^{9}$ The evidence taken into account could then be either $e=x$ as before or $e=(x, c)$. Both $x$ and $c$ are specific to the particular dispute. But would taking $c$ into account be useful?

In the present context, the informational value of $c$ is nil from the point of view of surplus maximization. That is, the possibility for courts of conditioning their ruling on both $c$ and $x$ cannot increase the parties' ex ante surplus, compared to conditioning on $x$ alone. Irrespective of $c$, surplus maximization is obtained if courts rule that quality is low when $x<\widehat{x}_{S}$ and high when $x>\widehat{x}_{S}$, where $\widehat{x}_{S}$ is defined as before by $f_{l}\left(\widehat{x}_{S}\right)=f_{h}\left(\widehat{x}_{S}\right)$. Thus, if the parties can choose the court's decision rule, they may as well require $c$ to be disregarded or rejected as inadmissible evidence. In fact, one suspects that declaring $c$ inadmissible may be useful in that it may make it easier for courts to hold 'neutral' priors concerning the seller's action.

Suppose by contrast that the parties must deal with truth-seeking courts. If $c$ is admissible, the court would up-date its overall prior on the basis of $e=(x, c)$. This can be decomposed in two steps. First, observing $c$, it updates to $\theta(c)$ defined as the equilibrium probability that a seller with $\operatorname{costs} c$

\footnotetext{
${ }^{9}$ For simplicity, I nevertheless assume that $c$ is non contractible. Relaxing this assumption would not affect the argument.
} 
delivered high quality. Secondly, taking $x$ into account it up-dates to

$$
\mu_{1}(x, c)=\frac{\theta(c) f_{h}(x)}{\theta(c) f_{h}(x)+(1-\theta(c)) f_{l}(x)}
$$

As in the preceding section a truth-seeking court rules that high quality has been supplied if $\mu_{1}(x, c)>1 / 2$. The difference is that the critical values for $x$ now depend on $c$ and are of the form $\widehat{x}_{T}(c)$.

A Perfect Bayesian Equilibrium in which high quality is supplied with positive probability is now characterized as follows. First, a seller with cost $c>\widehat{c}_{S}$ never supplies high quality, in other words $\theta(c)=0$ in that case. A seller with $c \leq \widehat{c}_{S}$ randomizes with probability $\theta(c)$ between high and low, where $\theta(c)$ and $\widehat{x}_{T}(c)$ satisfy:

$$
\begin{gathered}
{\left[F_{l}\left(\widehat{x}_{T}(c)\right)-F_{l}\left(\widehat{x}_{T}(c)\right)\right] v=c,} \\
\frac{f_{l}\left(\widehat{x}_{T}(c)\right)}{f_{h}\left(\widehat{x}_{T}(c)\right)}[1-\theta(c)]=\theta(c) .
\end{gathered}
$$

The first condition states that the seller is indifferent between high and low quality and therefore may randomize. The second condition follows from $\mu_{1}\left(\widehat{x}_{T}(c), c\right)=1 / 2$, meaning that the court would rule that high quality has been supplied if $x>\widehat{x}_{T}(c)$ for a seller with cost characteristics $c$. From the foregoing equations, it is easily verified that $\widehat{x}_{T}(c)$ and $\theta(c)$ are respectively increasing and decreasing. Hence courts need a more convincing $x$ to rule against a low $c$ seller.

Whether it is in the ex ante interest of the parties to allow truth-seeking courts to observe $c$ is ambiguous. It is easy to produce situations where the parties are worse off and this may in fact be the more prevalent case. The reason is that sellers who would have supplied high quality when only $x$ is admissible will now randomize between high and low. The off-setting effect is that some sellers will also randomize who would not have delivered high 
quality when only $x$ is admissible. The number of such sellers will tend to be small if the cut-off $\widehat{c}_{T}$ under $x$ alone does not differ too much from the surplus-maximizing $\widehat{c}_{S}$.

The present results have been derived in a somewhat restrictive framework. In particular, the submission of evidence was costless and parties were assumed to have access to the same body of evidence, which reduces the scope for manipulating the evidence presented to the third-party. Nevertheless, the general thrust of the argument should hold in a more complex environment. That is, in disputes concerning the fulfillment of contractual commitments and where performance is imperfectly verifiable, it is generally not in the ex ante interest of the parties that truth-seeking be the criterion for court rulings. Furthermore, it should generally be in the interest of the parties that some information be disregarded, as in the standard 'rules of evidence' in common law.

\section{References}

COOTER, R. and J. UHLEN [2000], Law and Economics, 3rd ed., AddisonWesley, Reading.

DAUGHETY, A. F. and J. F. REINGANUM [2000a], "On the economics of trials: adversarial process, evidence, an equilibrium bias", Journal of Law, Economics and Organization, 16, 365-395.

DAUGHETY, A. F. and J. F. REINGANUM [2000b], "Appealing judgments", Rand Journal of Economics, 31, 502-526.

DEMOUGIN, D. and C. FLUET [2002], "Preponderance of evidence", CESifo WP no 725. 
FLUET, C. [1999], "Régulation des risques et insolvabilité: le rôle de la responsabilité pour faute en information imparfaite", Actualité Économique, 75(1-3), 379-400.

FROEB, L. and B. KOBAYASHI [1996], "Naive, biased, yet Bayesian: can juries interpret selectively-produced evidence?", Journal of Law, Economics and Organization, 12, 257-276.

HYLTON, K. N. [1990], "Costly litigation and legal error under negligence", Journal of Law, Economics, and Organization 6(2), 433-452.

KAPLOW, L. and SHAVELL [1994], "Accuracy in the determination of liability", Journal of Law and Economics, 37, 1-15.

LEWIS, T. and M. POITEVIN [1997], "Disclosure of information in regulatory proceedings", Journal of Law, Economics and Organization 13, 50-73.

MILGROM, P. [1981]: "Good news and bad news: Representation theorems and applications", Bell Journal of Economics, 12:380-391.

MILGROM, P. and J. ROBERTS [1986], "Relying on the information of interested parties", Rand Journal of Economics 17, 18-32.

POLINSKY, M. A. and S. SHAVELL [1989], "Legal error, litigation, and the incentive to obey the law", Journal of Law, Economics and Organization 5, 99-108.

POSNER, R. A. [1999], "An economic approach to the law of evidence", Stanford Law Review 51, 1477-1546. 


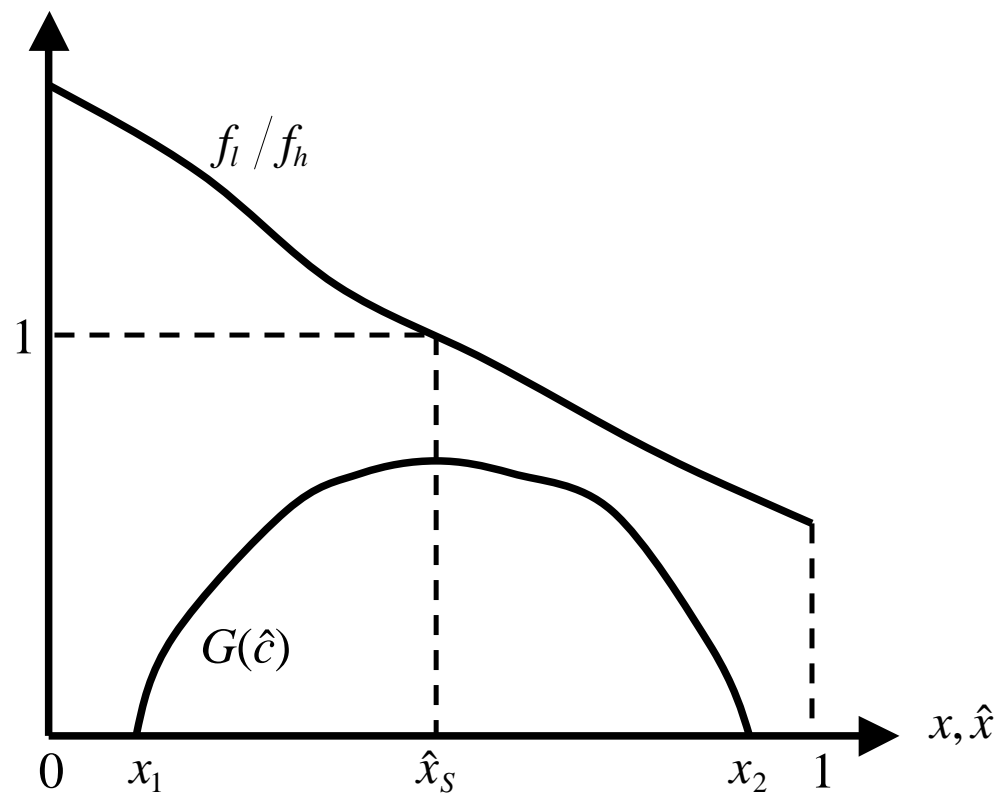

Figure 2a

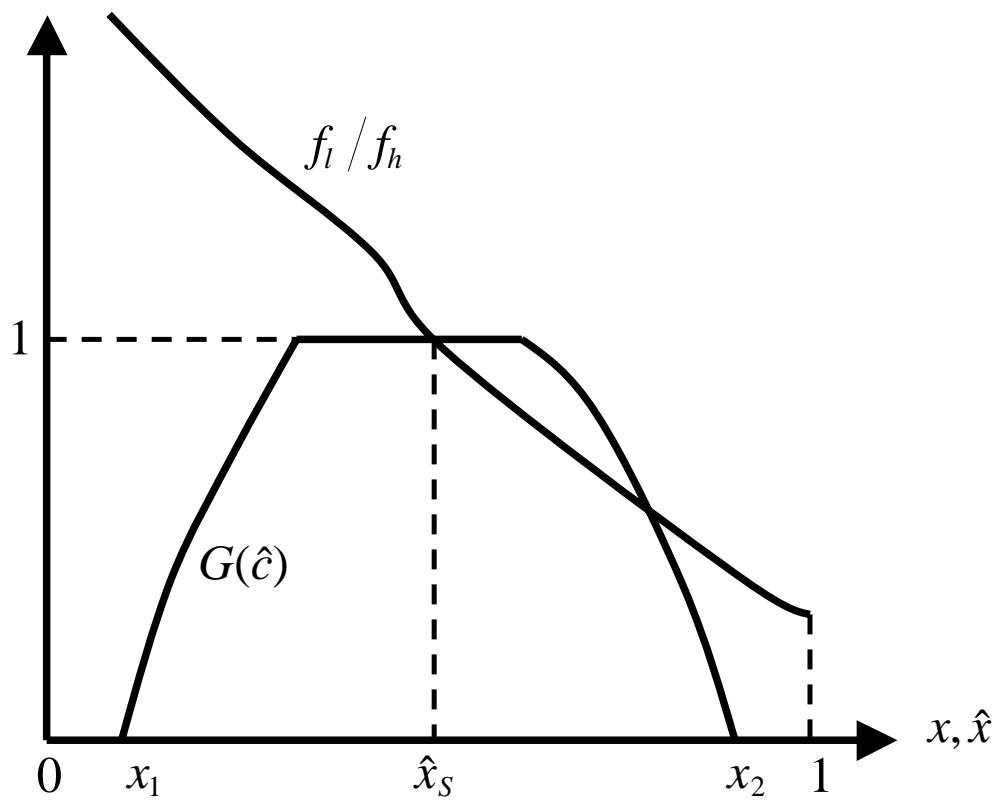

Figure $2 b$ 


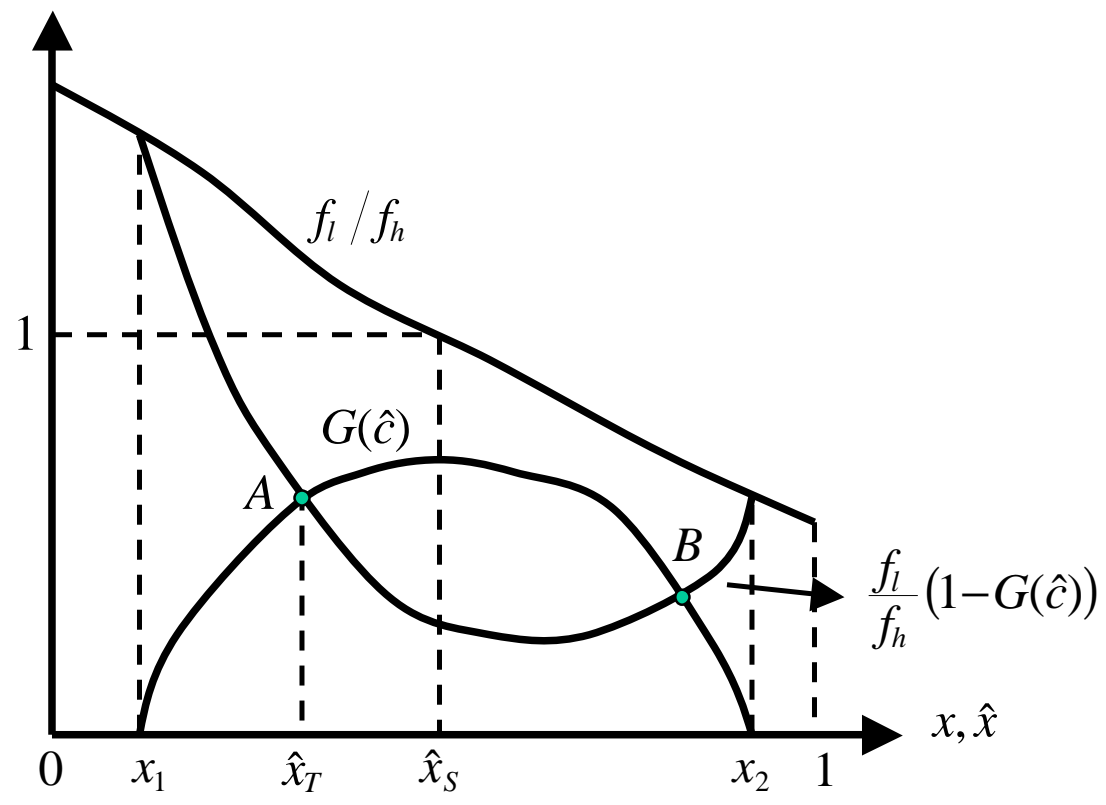

Figure $3 \mathrm{a}$

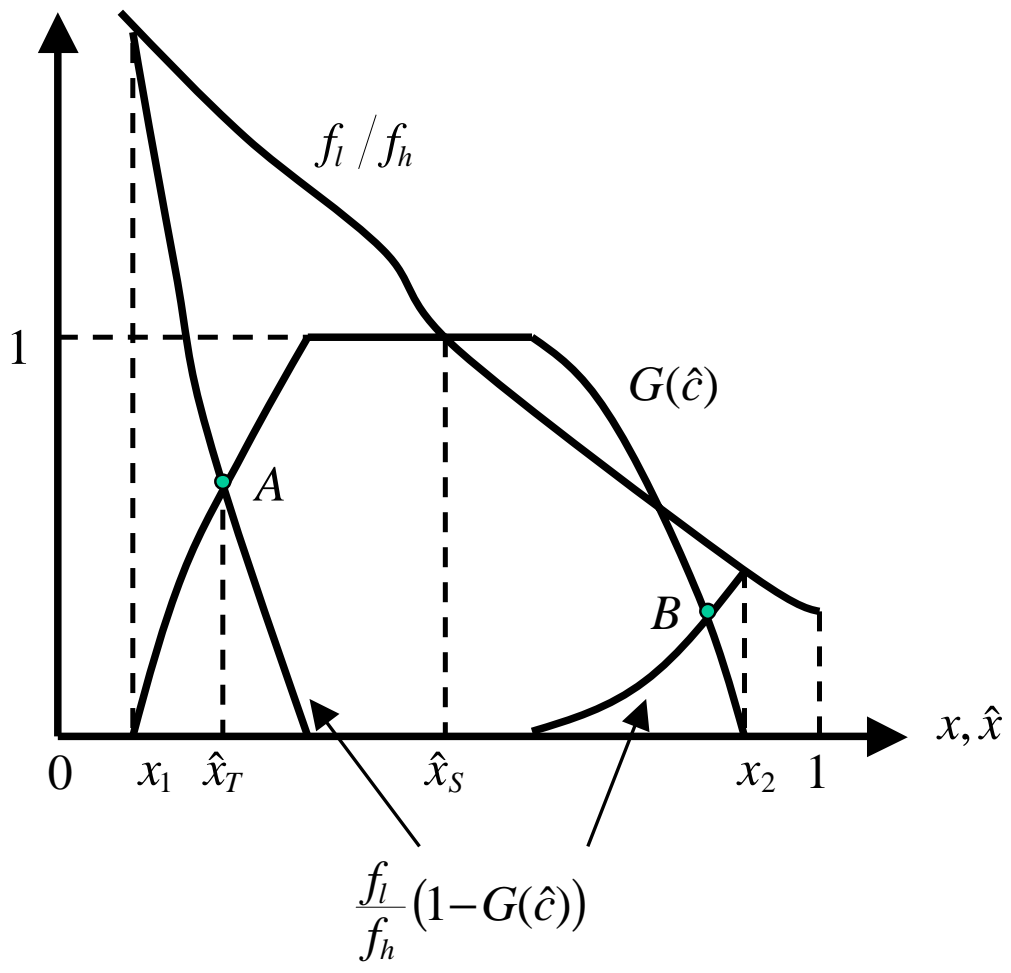

Figure $3 b$ 


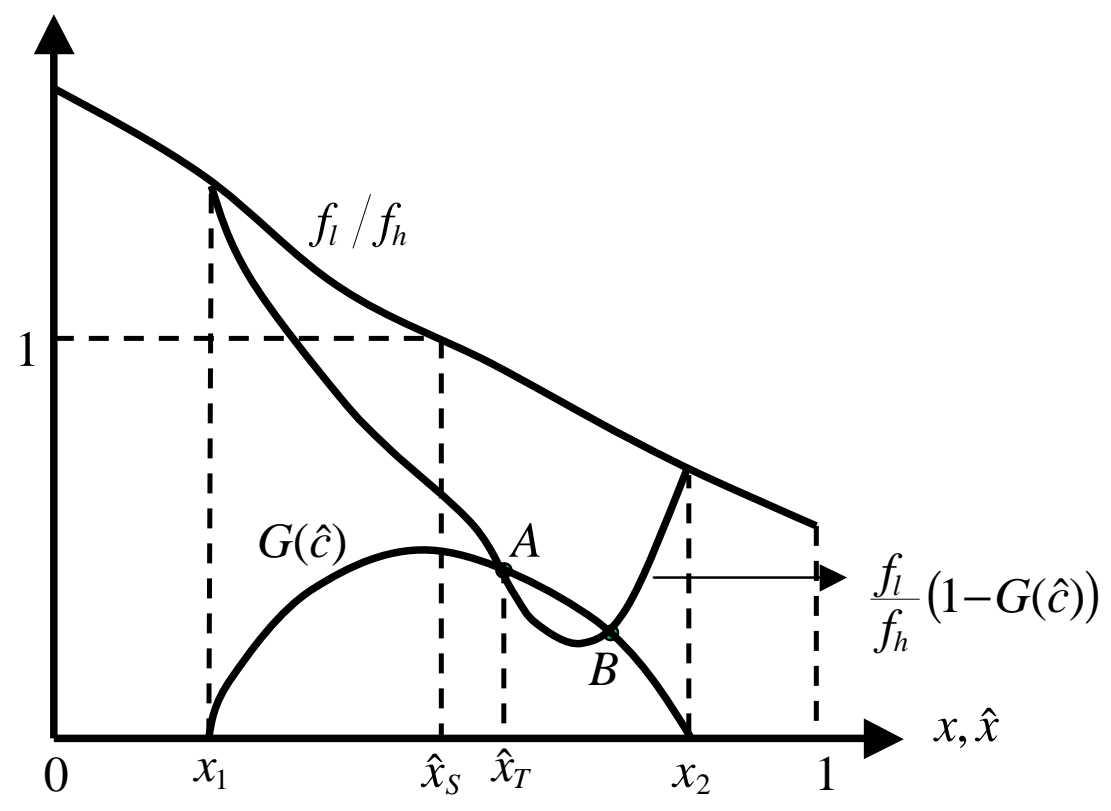

Figure $3 c$ 